\title{
Erratum to: The effects of foot position and orientation on inter- and intra-foot coordination in standing postures: a frequency domain PCA analysis
}

\author{
Zheng Wang · Peter C. M. Molenaar · Karl M. Newell
}

Published online: 28 July 2013

(C) Springer-Verlag Berlin Heidelberg 2013

Erratum to: Exp Brain Res

DOI 10.1007/s00221-013-3627-9

In the original publication of this article, the second author's initials were published incorrectly. The correct name should read as Peter C. M. Molenaar and not Peter M. C. Molenaar.

The online version of the original article can be found under doi:10.1007/s00221-013-3627-9.

Z. Wang $(\bowtie) \cdot$ K. M. Newell

Department of Kinesiology, The Pennsylvania State University,

23 Rec Building, University Park, PA 16802, USA

e-mail: zxw117@psu.edu

P. C. M. Molenaar

Department of Human Development and Family Studies,

The Pennsylvania State University, University Park, USA 